\title{
Assessment of human resources capacity of pharmaceutical warehouses in Cameroon
}

\author{
Samuel Ottu Ayuk*, Ojong Ntane Agbor, Felix Tanyi \\ From The 2nd People that Deliver (2nd PtD) Global Conference on Human Resources in Supply Chain \\ Management \\ Copenhagen, Denmark. 29-30 October 2014
}

\begin{abstract}
Background
Cameroon's health system is based on a pyramidal model, with three levels: central, intermediate and peripheral. This report describes the key findings of the assessments of the human resources of the Central Medical Stores (CENAME) and the 10 regional pharmaceutical supply centres (CAPRs) operating the public supply chain for pharmaceuticals and health commodities in Cameroon. The central level consists of the $\mathrm{MOH}$ whose main role is to define national strategy and policy, as well as of national-level hospital. The intermediate level consists of 10 regional delegation of public health, which provides technical support, coordination, oversight and supervision of health districts. This level also includes regional hospitals. The main objective of this assessment was to develop an improvement plan aimed at strengthening the human resources capacity in the public pharmaceutical sector in Cameroon at national and regional level.
\end{abstract}

\section{Method}

A tailor made tool was developed based on existing assessment tools, the World Health Organization good distribution practices for pharmaceutical products, and Cameroon's Good distribution practices for health products, and adapted to the local context. Data collected during the field visits were analysed identifying the strengths, weaknesses and recommendations.

\section{Results}

Most of the CAPRs have competent staff that are sufficient in number. Some CAPRs were overstaffed - mainly with regards to operational staff - relative to the current workload. It is not uncommon that a staff member occupies

* Correspondence: Osa_pharmacy@yahoo.com

South West Regional Fund for Health Promotion, Regional Pharmaceutical Supply Center, Yaoundé, Cameroon man resources. Training is essential for an efficient not competent. The unavailability of work based tools is also a challenge.

Published: 17 December 2014

\section{doi:10.1186/2052-3211-7-S1-P9}

Cite this article as: Ayuk et al:: Assessment of human resources capacity of pharmaceutical warehouses in Cameroon. Journal of Pharmaceutical Policy and Practice 2014 7(Suppl 1):P9. 